\title{
Composition and genetic diversity of picoeukaryotes in subtropical coastal waters as revealed by 454 pyrosequencing
}

\author{
Man Kit Cheung ${ }^{1}$, Chun Hang $\mathrm{Au}^{1}$, Ka Hou Chu, Hoi Shan Kwan and Chong Kim Wong \\ Department of Biology, The Chinese University of Hong Kong, Shatin, New Territories, Hong Kong SAR, China
}

\begin{abstract}
Information on genetic diversity of picoeukaryotes $(<2-3 \mu \mathrm{m})$ comes mainly from traditional gene cloning and sequencing, but this method suffers from cloning biases and limited throughput. In this study, we explored the feasibility of using the cloning-independent and massively parallel 454 pyrosequencing technology to study the composition and genetic diversity of picoeukaryotes in the coastal waters of the subtropical western Pacific using the hypervariable V4 region of the 18S rRNA gene. Picoeukaryote assemblages between two sites with different hydrography and trophic status were also compared. The approach gave a high coverage of the community at genetic difference $\geqslant 5 \%$ but still underestimated the total diversity at a genetic difference $\leqslant 2 \%$. Diversity of picoeukaryotes was higher in an oligomesotrophic bay than in a eutrophic bay. Stramenopiles, dinoflagellates, ciliates and prasinophytes were the dominant groups comprising approximately $27,19,11$ and $11 \%$, respectively, of the picoeukaryotes. Water samples collected from the two bays contained different high-level taxonomic groups and phylotype operational taxonomic units of picoeukaryotes. Our study represents one of the first and most comprehensive examinations of marine picoeukaryotic diversity using the $\mathbf{4 5 4}$ sequencing-by-synthesis technology.
\end{abstract}

The ISME Journal (2010) 4, 1053-1059; doi:10.1038/ismej.2010.26; published online 25 March 2010

Subject Category: Microbial ecology and functional diversity of natural habitats

Keywords: 18S; microbial diversity; Pacific Ocean; picophytoplankton; picoplankton; pyrosequencing

\section{Introduction}

Picoeukaryotes are eukaryotes smaller than $2-3 \mu \mathrm{m}$ in diameter. They occur in aquatic environments worldwide and are considered as fundamental components of marine ecosystems in the oceans (Sherr and Sherr, 2000). They contribute significantly to biomass and primary production and are particularly important in nutrient-rich coastal waters in which they are most abundant (Li, 1994; Worden and Not, 2008). During the last decade, studies based on cloning and sequencing of the $18 \mathrm{~S}$ rRNA gene have revealed an unexpected diversity among picoeukaryotes in the oceans (Díez et al., 2001; López-García et al., 2001; Moon-van der Staay et al., 2001). Unfortunately, this approach suffers from potential cloning biases that may mask the real diversity of the community under study (Forns et al., 1997). In addition, community diversity may

Correspondence: CK Wong, Department of Biology, Simon FS Li Marine Science Laboratory, The Chinese University of Hong Kong, Shatin, New Territories, Hong Kong, China.

E-mail: chongkimwong@cuhk.edu.hk

${ }^{1}$ These authors contributed equally to this work.

Received 10 September 2009; revised 28 January 2010; accepted 11 February 2010; published online 25 March 2010 also be greatly underestimated by the limited throughput of the method (Bent and Forney, 2008).

The newly emerged 454 sequencing-by-synthesis technology is cloning independent and massively parallel (Margulies et al., 2005). The diversity of bacteria (Sogin et al., 2006) and archaea (Galand et al., 2009) in open oceans has been investigated with high-throughput amplicon sequencing targeting the hypervariable V6 region of the 16S rRNA gene. Targeting the V9 hypervariable region of the 18S rRNA gene, this technology has also been applied to marine protists recently (Amaral-Zettler et al., 2009). However, to the best of our knowledge, no similar studies have been carried out on marine picoeukaryotes. In this study, we explored the feasibility of using the 454 pyrosequencing technology to investigate the diversity and community composition of picoeukaryote assemblages in subtropical coastal waters of the western Pacific. Picoeukaryote assemblages between two sites with different hydrography and trophic status were also compared.

\section{Materials and methods}

Sample collection and DNA extraction

Surface seawater samples $(\sim 2.5 \mathrm{l})$ were collected from two bays in northeastern Hong Kong in April 
Table 1 Sampling conditions and sequence characteristics of the two sites

\begin{tabular}{lcc}
\hline & Mirs Bay & Tolo Harbor \\
\hline Coordinates & $22^{\circ} 30.735^{\prime} \mathrm{N}$, & $22^{\circ} 25.920^{\prime} \mathrm{N}$, \\
& $114^{\circ} 21.546^{\prime} \mathrm{E}$ & $114^{\circ} 13.110^{\prime} \mathrm{E}$ \\
Temperature $\left({ }^{\circ} \mathrm{C}\right)$ & 21.8 & 23.0 \\
Dissolved oxygen $\left(\mathrm{mg} \mathrm{l}^{-1}\right)$ & 7.87 & 7.89 \\
Salinity (\%) & 33.5 & 32.5 \\
Chlorophyll $a\left(\mu \mathrm{g} \mathrm{l}^{-1}\right)$ & 1.92 & 9.06 \\
Total reads & 100911 & 87392 \\
Average read length $(\mathrm{bp})$ & 259 & 260 \\
Trimmed tags & 87789 & 272 \\
Average tag length $(\mathrm{bp})$ & 272 & 48208 \\
Tags after BLASTN & 61671 & \\
\hline
\end{tabular}

Trimmed tags are sequence reads remaining after the removal of lowquality and nontarget reads. Tags after BLASTN are tags with $\geqslant 95 \%$ query coverage and top match identity to GenBank entries.

2007. Tolo Harbor (TH) is a landlocked bay with a long history of eutrophication (Wear et al., 1984; Chau, 2007). Located outside TH, Mirs Bay (MB) is relatively unpolluted and more exposed to ocean currents from the South China Sea (Hong Kong Environmental Protection Department, 2003). Water samples were filtered through a $200 \mu \mathrm{m}$ mesh sieve immediately to remove most of the mesozooplankton and large particles. Water temperatures, salinities and dissolved oxygen levels were measured on board using a Hydrolab sensor (Austin, TX, USA). In the laboratory, chlorophyll $a$ concentrations were determined using a Turner Designs 10-AU fluorometer (Sunnyvale, CA, USA) as described by Wong and Wong (2003). At the time of sample collection, chlorophyll $a$ concentration was $9.1 \mu \mathrm{g} \mathrm{l} \mathrm{l}^{-1}$ in $\mathrm{TH}$ and $1.9 \mu \mathrm{gl} \mathrm{l}^{-1}$ in $\mathrm{MB}$ (Table 1). On the basis of these values, TH and MB were considered to be eutrophic and oligomesotrophic, respectively (Molvaer et al., 1997).

Two liters of water was prefiltered through $3 \mu \mathrm{m}$ pore size Nuclepore membranes (Whatman, Piscataway, NJ, USA) and the microbial biomass was then collected onto a GF/F filter (Whatman). A gentle vacuum $(<20 \mathrm{~cm} \mathrm{Hg}$ ) created by a hand pump was used to facilitate the filtration processes. The filter was then immersed in DNA lysis buffer $(0.75 \mathrm{M}$ sucrose, $40 \mathrm{mM}$ EDTA, $50 \mathrm{~mm}$ Tris-HCl ( $\mathrm{pH}$ 8)), immediately frozen in liquid nitrogen and stored at $-80{ }^{\circ} \mathrm{C}$ until DNA extraction. DNA was extracted after the cetyltrimethylammonium bromide extraction procedure (Doyle and Doyle, 1990).

\section{PCR and pyrosequencing}

PCR was performed using 454 sequencing adaptorlinked primers flanking the hypervariable V4 region of the 18S rRNA gene: A-528F (5'-gcctccctcgcgccatc ag-GCGGTAATTCCAGCTCCAA-3') and B-706R ( $5^{\prime}$-gc cttgccagcccgctcag-AATCCRAGAATTTCACCTCT-3') (adaptor sequences shown in lowercase) (Elwood et al., 1985). PCR mixtures ( $50 \mu \mathrm{l})$ were prepared in duplicate and each contained $2 \mu$ of DNA template,
$5 \mu \mathrm{l}$ of $10 \times$ PCR buffer $(50 \mathrm{~mm} \mathrm{KCl}, 10 \mathrm{mM}$ Tris-HCl and $1.5 \mathrm{mM} \mathrm{MgCl}_{2}$ ), $200 \mu \mathrm{M}$ of dNTP, $0.2 \mu \mathrm{M}$ of each primer and 2.5 U Taq polymerase (Promega, Madison, WI, USA). The PCR thermal regime consisted of an initial denaturation of $3 \mathrm{~min}$ at $94{ }^{\circ} \mathrm{C}$, followed by 30 cycles of $30 \mathrm{~s}$ at $94^{\circ} \mathrm{C}, 30 \mathrm{~s}$ at $60{ }^{\circ} \mathrm{C}, 1 \mathrm{~min}$ at $72{ }^{\circ} \mathrm{C}$ and a final cycle of $5 \mathrm{~min}$ at $72{ }^{\circ} \mathrm{C}$. PCR products were pooled and purified with the Qiaquick gel purification kit according to the manufacturer's instructions (Qiagen, Hilden, North Rhine-Westphalia, Germany). DNA concentration and quality were determined with a NanoDrop 1000 spectrophotometer (Wilmington, DE, USA).

Pyrosequencing of PCR products was performed on a Genome Sequencer FLX system at 454 Life Sciences (Branford, CT, USA). Sequences and quality scores from our pyrosequencing run were submitted to the NCBI short read archive (accession number SRA009090). Raw sequence reads were filtered before subsequent analyses to minimize the effects of random sequencing errors (Huse et al., 2007). Briefly, we eliminated sequence reads that (1) did not perfectly match the proximal PCR primer, (2) were too short $(<244 \mathrm{bp})$ or too long $(>302 \mathrm{bp})$, as determined by the sequence length distribution plots or (3) contained one or more ambiguous base(s) (N(s)).

\section{Assignment of phylotype OTUs}

Phylotype operational taxonomic units (OTUs) were assigned according to the best BLASTN hit (Altschul et al., 1990) against NCBI nucleotide sequence database NT (as of August 2008) with the following parameters: $E$ value $=10^{-5}$, minimum query coverage $=95 \%$ and minimum identity $=95 \%$. Taxonomic group assignment of reads resembling GenBank sequences from environmental clones was obtained using the web-based software package KeyDNAtools as described by Guillou et al. (2008). Nontarget reads belonging to viruses, bacteria or metazoa were removed from further analyses.

\section{Assignment of similarity-based OTUs and species richness estimators}

Sequence reads from each sample were clustered to give similarity-based OTUs using cd-hit-est ( $\mathrm{Li}$ and Godzik, 2006) with minimum sequence identity set to $90,95,98$ or $100 \%$. Parametric rarefaction curves were calculated in steps of 1000 specimens using Analytic Rarefaction (v 1.3, http://www.uga. edu/strata/software/anRareReadme.html). Nonparametric species richness ACE and classic Chao1 estimates were calculated using EstimateS (v 8, http:// viceroy.eeb.uconn.edu/estimates).

\section{Results}

Characteristics of the pyrosequencing run

A total of 188303 sequence reads with an average length of about $260 \mathrm{bp}$ were generated in a single run 
of 454 pyrosequencing from the two water samples (Table 1). The filtering process removed about $12 \%$ of the raw sequence reads, leaving 87789 and 76817 high-quality target tags from the $\mathrm{MB}$ and TH samples, respectively. The average tag length was improved to about $272 \mathrm{bp}$. After BLAST searching, 61671 and 48208 sequences with $\geqslant 95 \%$ query coverage and top match identity remained for samples collected from $\mathrm{MB}$ and $\mathrm{TH}$, respectively.

\section{Composition and distribution of the picoeukaryotic} assemblages

Trimmed tags were grouped under at least 19 highlevel taxonomic groups (Supplementary Table 1) and over $93 \%$ of them fell into one of the nine major groups (Figure 1). Stramenopiles, dinoflagellates, ciliates and prasinophytes comprising about $27 \%$, $19 \%, 11 \%$ and $11 \%$, respectively, of the picoeukaryotes were the dominant groups. Although stramenopiles and dinoflagellates together contributed more than half $(55.9 \%)$ of the total community in the sample from $\mathrm{TH}$, five groups (stramenopiles, prasinophytes, dinoflagellates, ciliates and the novel alveolates group III (NAGIII)) shared similar contributions (each between $10 \%$ and $25 \%$ ) for the sample from MB. NAGI, NAGIII and prasinophytes were at least threefold more abundant in MB than in TH. Conversely, the abundance of picobiliphytes and cercozoans in $\mathrm{TH}$ at least doubled than those in MB. The relative contributions of NAGII, ciliates and dinoflagellates were almost comparable between samples from TH and MB. Dinophyceae and stramenopiles were more abundant in $\mathrm{TH}$, but the relative contributions of their phylotype OTUs were higher in MB (Supplementary Figure). Alternatively, there was more NAGIII in MB than in TH, although both samples shared comparable contributions of phylotype OTUs.

In both samples, the top 20 phylotype OTUs each contributed at least $1 \%$ and together represented about $60 \%$ of the entire picoeukaryote community

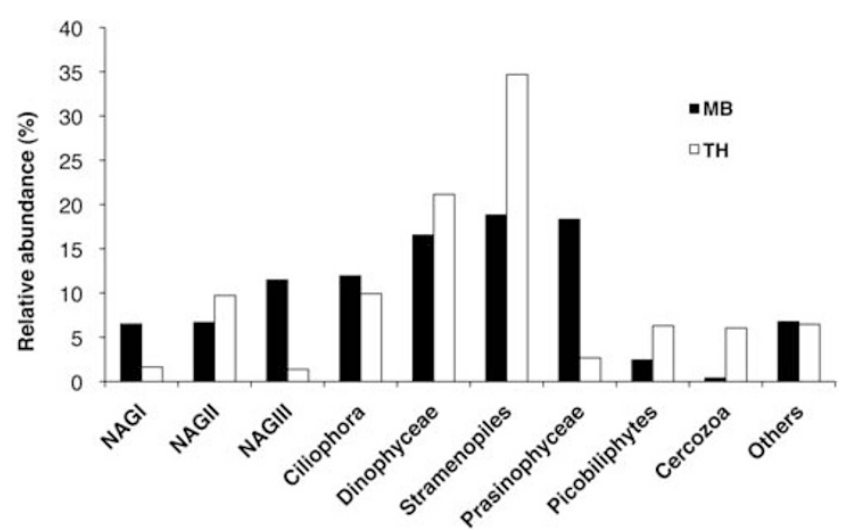

Figure 1 Relative abundance of the nine dominant high-level taxonomic groups of picoeukaryotes. MB, Mirs Bay; TH, Tolo Harbor; NAG, novel alveolates group.
(61.7\% in $\mathrm{MB}$ and $56.7 \%$ in $\mathrm{TH}$ ) (Table 2). In addition, more than half of the OTUs represented uncultured environmental clones (MB, 14; TH, 13). Although sequence reads resembling six GenBank entries (Pseudochattonella verruculosa, Verrucophora farcimen, Pterosperma cristatum, uncultured Dinophyceae clone dhot2b10, AMT15_1B_26 and uncultured NAGII clone SA1_4G10) were common in both bays, the abundance of all other top phylotype OTUs differed between TH and MB. More than half of the top phylotype OTUs were at least four times more abundant in terms of percentage contribution in one sample than in the other.

\section{Diversity of the picoeukaryotic assemblages}

The coverage of libraries at cluster distances $\geqslant 0.05$ was high for both samples, with rarefaction curves reaching saturation. However, rarefaction curves at a cluster distance of 0.02 were still in an increasing trend (Figure 2). The numbers of OTUs detected were generally close to those estimated by the nonparametric ACE and Chao1 estimators at cluster distances $\geqslant 0.05$, with percentages of detected OTUs/estimated OTUs over $75 \%$ (Table 3), but the difference between the observed and estimated values at cluster distances $\leqslant 0.02$ was large, especially when identical tags were grouped into unique OTUs, with percentages of detected OTUs/estimated OTUs less than $20 \%$.

\section{Discussion}

\section{Methodology}

In recent years, the cloning and sequencing approach has been widely used to study the diversity and community composition of picoeukaryotes (Díez et al., 2001; López-García et al., 2001; Moon-van der Staay et al., 2001). However, with an examination of typically 100 clones per library (Vaulot et al., 2008), the data generated by this approach only provide general information on the structure of picoeukaryote communities but are not sufficient for meaningful comparisons among libraries. In this study, water samples were collected from two sites of different trophic status and about 100000 sequence reads were derived from each water sample to facilitate an in-depth investigation into the structure of the picoeukaryote assemblages. However, as only one sample per site was examined, conclusions about picoeukaryotic communities are limited to the respective samples.

In a previous study at the same two sites, picoeukaryotic diversity was studied using the traditional cloning and sequencing method (Cheung et al., 2008). Sequencing in partial PCR products amplified using the widely adopted primer set Euk328f and Euk329r (Moon-van der Staay et al., 2001) with the primer Euk528f (Elwood et al., 1985) allowed us to recover at least 19 high-level taxonomic 
Table 2 Top 20 phylotype OTUs in samples from the two sampling sites

\begin{tabular}{|c|c|c|c|c|c|c|c|c|c|c|}
\hline \multirow[t]{2}{*}{ No. } & \multicolumn{5}{|c|}{$M B$} & \multicolumn{5}{|c|}{$T H$} \\
\hline & $\%$ & $C \%$ & $A N$ & $A F$ & GenBank ID & $\%$ & $C \%$ & $A N$ & $A F$ & GenBank ID \\
\hline 1 & 8.5 & 0.8 & EU780604 & NAGIII & UC AMT15_1B_36 & 4.9 & NS & DQ470662 & STRA & Heterosigma akashiwo \\
\hline 2 & 7.9 & 0.3 & DQ120009 & CILI & UC NW414.24 & 4.6 & 0.2 & DQ367045 & STRA & Aplanochytrium sp. \\
\hline 3 & 7.6 & NS & EU143384 & PRAS & UC PROSOPE.C1-80m.96 & 4.6 & 0.6 & EU545747 & CILI & UC 9_153 \\
\hline 4 & 4.9 & 3.4 & AB217630 & STRA & Pseudochattonella verruculosa & 4.5 & 1.3 & EF526908 & NAGII & UC SA-1_4G10 \\
\hline 5 & 4.8 & 3.2 & AM075624 & STRA & Verrucophora farcimen & 3.8 & 3.4 & EU500021 & DINO & UC dhot2b10 \\
\hline 6 & 3.4 & 3.8 & EU500021 & DINO & UC dhot2b10 & 3.8 & 0.6 & EU500204 & DINO & UC hotxp3a1 \\
\hline 7 & 3.1 & NS & EU143470 & PRAS & UC PROSOPE.E1-80m.61 & 3.4 & 4.9 & AB217630 & STRA & Pseudochattonella verruculosa \\
\hline 8 & 3.1 & NS & EU143463 & PRAS & UC PROSOPE.EU-30m.113 & 3.2 & 4.8 & AM075624 & STRA & Verrucophora farcimen \\
\hline 9 & 2.6 & 0.1 & EF172986 & NAGI & UC SSRPD84 & 3.1 & 0.8 & DQ222873 & PICO & UC HE000803.72 \\
\hline 10 & 2.1 & 0.1 & EF173005 & NAGII & UC H02N5 & 2.8 & NS & AB252743 & CERC & UC NAMAKO-3 \\
\hline 11 & 1.9 & 1.5 & EU780595 & DINO & UC AMT15_1B_26 & 2.7 & 0.6 & AY485503 & STRA & Eucampia antarctica \\
\hline 12 & 1.8 & 1.1 & AY664962 & DINO & UC SCM37C27 & 2.7 & 0.3 & EU087273 & CILI & UC 9_52 \\
\hline 13 & 1.7 & NS & DQ504316 & NAGI & UC LC22_5EP_6 & 2.3 & 0.1 & EU087251 & CERC & UC 9_25 \\
\hline 14 & 1.7 & 0.4 & EU780607 & NAGIII & UC AMT'15_1B_ $\_40$ & 1.7 & 1.0 & AJ010407 & PRAS & Pterosperma cristatum \\
\hline 15 & 1.4 & 0.9 & AM075625 & STRA & Chattonella verruculosa & 1.6 & 0.2 & EF527119 & STRA & UC SA2_1C5 \\
\hline 16 & 1.3 & 4.5 & EF526908 & NAGII & UC SA1_4G10 & 1.6 & 0.2 & EU733829 & DINO & UC 2C_F-F07 \\
\hline 17 & 1.2 & 0.4 & AF063239 & RADI & Arthracanthida sp. & 1.6 & 0.1 & EF526986 & STRA & UC MIF_CilE6 \\
\hline 18 & 1.1 & 0.2 & EF492500 & DINO & Heterocapsa pygmaea & 1.5 & 1.9 & EU780595 & DINO & UC AMT̄15_1B_26 \\
\hline 19 & 1.0 & 1.7 & AJ010407 & PRAS & Pterosperma cristatum & 1.3 & 0.2 & EF173006 & NAGII & $\mathrm{UC}$ Q2A03 \\
\hline 20 & 1.0 & NS & EU500001 & CILI & UC dhot2b7 & 1.2 & 0.4 & U14387 & STRA & Pseudopedinella elastica \\
\hline
\end{tabular}

Abbreviations: MB, Mirs Bay; TH, Tolo Harbor; C\%, percentage of the OTU in the other sample (NS = value $<0.05$ ); AN, accession number; AF, affiliation; NAG, novel alveolates group; CILI, Ciliophora; PRAS, Prasinophyceae; STRA, stramenopiles; DINO, Dinophyceae; RADI, radiozoa; PICO, picobiliphytes; CERC, cercozoa; UC, uncultured clone.

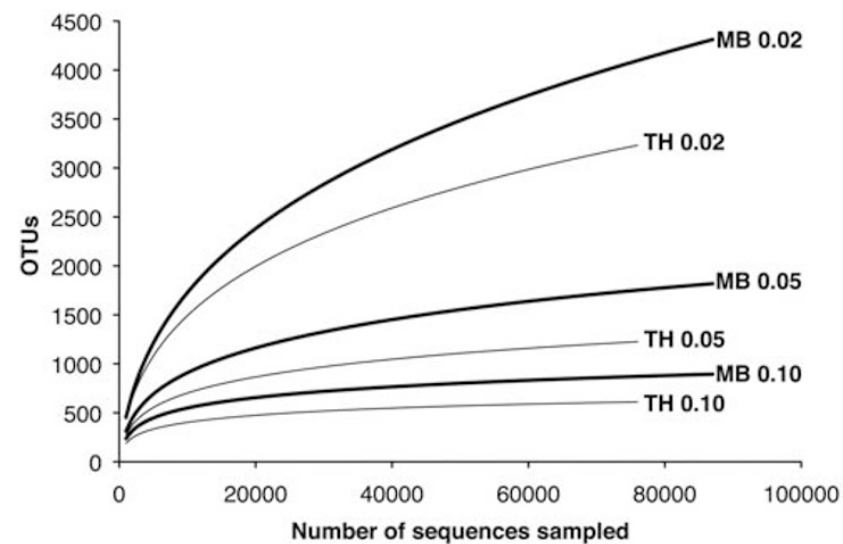

Figure 2 Rarefaction curves of similarity-based operational taxonomic units (OTUs) at cluster distance values of $0.02,0.05$ and 0.10. MB, Mirs Bay; TH, Tolo Harbor.

groups of picoeukaryotes. In this study, at least 19 high-level taxonomic groups were recovered using the primer set, A-528F and B-706R, which targets the same hypervariable V4 region (Supplementary Table 1). Although the dominant groups were retrieved by both methods, sequences belonging to nucleomorphs and ellobiopsids were only detected in the previous study, and sequences belonging to NAGIII, centrohelids and some other groups of chlorophytes apart from prasinophytes were only recovered in this study. However, except for NAGIII, which is a newly defined alveolates group (Guillou et al., 2008), all the other groups were only
Table 3 Similarity-based OTUs and species richness estimates of the two libraries

\begin{tabular}{lcrrr}
\hline Library & Cluster distance & Detected OTU & \multirow{2}{*}{ ACE } & Chao1 \\
\hline MB & 0.00 & 33209 & 172662 & 172718 \\
& 0.02 & 4326 & 6664 & 6670 \\
& 0.05 & 1823 & 2381 & 2385 \\
TH & 0.10 & 896 & 1075 & 1079 \\
& 0.00 & 30634 & 167610 & 167673 \\
& 0.02 & 3243 & 4657 & 4662 \\
& 0.05 & 1229 & 1545 & 1548 \\
& 0.10 & 612 & 699 & 702 \\
\hline
\end{tabular}

Abbreviations: MB, Mirs Bay; TH, Tolo Harbor.

represented in low abundance. The results reveal a comparable coverage of high-level taxonomic groups with the two methods using different primer sets targeting the same DNA region.

It is difficult to assign a correct taxonomic identity to tags that are too divergent from sequences available from the reference database, particularly when the database is not exhaustive enough, similar to the eukaryotic SSU rRNA database under investigation here. Thus, after BLAST searching, sequences that showed a query coverage or top match identity of $\leqslant 95 \%$ were excluded from further analyses. This stringent process removed about $30 \%$ of the MB and $37 \%$ of the $\mathrm{TH}$ trimmed tags but secured a more accurate taxonomic identification of the remaining reads. Indeed, a significant amount (up to about $30 \%$ ) of fairly divergent sequence tags, with GAST 
distances greater than 0.10 , was also recovered in a previous study of protists using the 454 technology (Amaral-Zettler et al., 2009). It is worth noting that as more sequences are accumulated in the database, the assigned taxonomic identity of tags with relatively low similarity to previous entries may change. Therefore, the results presented here were restricted to our current knowledge on picoeukaryotes.

Intrinsic errors of the 454 pyrosequencing technology could lead to overestimation of species richness. We followed the quality filtering strategy proposed by Huse et al. (2007), which ensures that the per-base error rates of GS20 pyrosequencing reads will be comparable or lower than the conventional Sanger sequencing method. However, an examination of the 16S rRNA genes of a single Escherichia coli strain by Kunin et al. (2009) suggested that diversity was still being overestimated in pyrosequencing data sets after the quality filtering process. According to their analysis, our diversity estimates at cluster distances of $0.10,0.05$ and 0.02 may have been overestimated by twofold, threefold and more than ninefold, respectively.

\section{Diversity of the picoeukaryotic assemblages}

Parametric rarefaction curves and nonparametric ACE and Chao1 estimators were used to estimate OTU richness in this study. The nonparametric richness estimators have been used in diversity studies of picoeukaryotes/protists only recently (Massana et al., 2004; Zuendorf et al., 2006; Countway et al., 2007). Using a 95\% phylotype cutoff, Countway et al. (2007) studied protistan diversity from 18S rRNA clone libraries and reported ACE and Chao1 values of around 400 for the euphotic zone of the Gulf Stream. Using 454 pyrosequencing technology and the same phylotype cutoff, Amaral-Zettler et al. (2009) obtained incidence-based ICE and Chao2 estimates of about 4000 for protistan diversity in a polluted estuary site off the coast of Massachusetts. For picoeukaryotic diversity, Massana et al. (2004) reported one of the highest Chao1 estimates of nearly 200 in an oligotrophic coastal site at Blanes Bay by grouping clones sharing the same RFLP patterns as unique OTUs. In this study, the calculated ACE and Chao1 estimates for picoeukaryotic diversity in subtropical coastal waters ranged from $\sim 700$ in the TH sample at a cluster distance of 0.10 to $\sim 6600$ in the $\mathrm{MB}$ sample at a cluster distance of 0.02 . These values are generally much higher than those published by other investigators for picoeukaryotic/protistan diversity. However, the above comparison is rough as it is difficult to compare estimates based on different OTU defining and/or sequencing strategies. Also, in contrast to prokaryotes, the copy number of SSU rRNA genes varies widely among eukaryotes (Zhu et al., 2005), which in turn may affect the estimates calculated. According to the correlation between cell length and SSU rRNA gene copy numbers of eukaryotes estimated by QPCR, picoeukaryotes are expected to have less than 10 copies of SSU rRNA genes.

Rarefaction curves predict that additional sampling would lead to significantly higher estimates of total diversity at a cluster distance of 0.02 , even by examining nearly 100000 sequences per sample (Figure 2). As this threshold corresponds roughly to the genus/species level of picoeukaryotes (Romari and Vaulot, 2004), the results suggest that further increasing the sampling effort would reveal more genera/species of picoeukaryotes in the water samples. This finding confirms that the diversity of picoeukaryotes is unexpectedly high and still largely unknown (Mackey et al., 2002).

A unimodal relationship between diversity and productivity for herbaceous vegetation has long been observed in terrestrial systems (Grime, 1973). Recent analysis of a global data set has revealed a similar pattern between marine phytoplankton diversity and phytoplankton biomass (Irigoien et al., 2004). Lefranc et al. (2005) used the cloning and sequencing method to study the genetic diversity of small eukaryotes $(<5 \mu \mathrm{m})$ in three lakes in France and reported a higher diversity in the oligomesotrophic lake than in the oligotrophic and eutrophic lakes. In this study, both parametric rarefaction curves and nonparametric richness estimators revealed a higher diversity of picoeukaryotes in the oligomesotrophic MB than in the eutrophic TH (Table 3, Figure 2). This finding is in good agreement with that of Lefranc et al. (2005) and provides further evidence on the classic unimodal diversity-productivity relationship.

\section{Composition and distribution of the picoeukaryotic assemblages}

Water samples collected from two bays along the subtropical Pacific coast harbored different assemblages of picoeukaryotes, as revealed by the few shared top phylotype OTUs (Table 2) as well as the differential contribution by the most represented groups (Figure 1).

Prasinophytes recovered from this study (Table 2) and from other environmental genetic libraries (Worden, 2006) included mainly uncultured Bathycoccus, Micromonas and Ostreococcus spp. within the order Mamiellales. These organisms are more common in coastal areas than in open oceans (Not et al., 2005). In our study, prasinophytes were more abundant in open waters of MB than in the eutrophic waters of the semi-enclosed TH (Figure 1). A similar result was found in our previous study using the cloning and sequencing strategy (Cheung et al., 2008). Viprey et al. (2008) reported a greater dominance by Micromonas and Ostreococcus environmental sequences in relatively mesotrophic waters than in oligotrophic coastal waters. Taken together, these results suggest that these genera are well adapted to coastal waters of intermediate 
productivity, although the role of water temperature should not be neglected (Lovejoy et al., 2007).

Picobiliphytes are a recently defined algal group with a phycobiliprotein-containing plastid (Not et al., 2007). Our previous study showed that picobiliphytes are prevalent in eutrophic waters (Cheung et al., 2008), and this finding is supported by the results obtained in this study (Figure 1). The repeated recovery of picobiliphytes in our samples also provides further evidence on their prevalence in subtropical waters (Cheung et al., 2008, Cuvelier et al., 2008). NAGIII, a newly defined alveolates group, contains environmental sequences from oceanic and coastal waters (Guillou et al., 2008). Since its recent discovery, little is known about its ecology. Our study provides information about its dominance in waters of lower productivity (Figure 1), but more evidence has to be provided for confirmation.

Most of the top phylotype OTU matches in the water sample from $\mathrm{MB}$ were from environmental studies performed in oceanic or coastal waters (Supplementary Table 2). In contrast, a noticeable number of OTUs in the water sample from TH were retrieved either from anoxic sediments or from water samples collected during algal blooms. For instance, the third most abundant phylotype OTU in the MB sample (uncultured prasinophyte clone PROSOPE.C1-80m.96) was retrieved from the Mediterranean Sea (Viprey et al., 2008), whereas the third most abundant OTU in the TH sample (uncultured ciliate clone 9_153) was recovered from the anoxic layer of the East Sea sediment in the northwestern Pacific (Park et al., 2008). In addition, stramenopiles, which have been found abundantly in anoxic and extreme environments (Stoeck and Epstein, 2003; Luo et al., 2005), seemed to dominate the TH sample (Figure 1). Because high levels of phytoplankton biomass could lead to hypoxia/ anoxia (Roman et al., 1993), the presence of OTUs with high adaptability to anoxic environments in the eutrophic waters of TH is not unexpected.

\section{Conclusions}

In this study, we successfully applied the massively parallel 454 sequencing-by-synthesis technology to describe the composition and genetic diversity of marine picoeukaryotes off the subtropical western Pacific coast. Our results showed that, even by examining nearly a 100000 sequences per sample, a greater sampling effort would likely harbor more taxa of picoeukaryotes. Water samples of different trophic status contained different high-level taxonomic groups and phylotype OTUs of picoeukaryotes. With the ultrahigh resolution power provided by 454 pyrosequencing, more in-depth examinations of picoeukaryotic diversity in various aquatic ecosystems are possible. In the future, this technology can be used to answer ecological questions related to spatial and temporal patterns as well as to identify ecological responses to changing environmental conditions that require an accurate characterization of community composition.

\section{Acknowledgements}

We thank YH Yung for sample collection, and CP Li and KC Cheung for technical assistance. The work was supported by research grants from the Research Committee, The Chinese University of Hong Kong.

\section{References}

Altschul SF, Gish W, Miller W, Myers EW, Lipman DJ. (1990). Basic local alignment search tool. J Mol Biol 215: 403-410.

Amaral-Zettler LA, McCliment EA, Ducklow HW, Huse SM. (2009). A method for studying protistan diversity using massively parallel sequencing of V9 hypervariable regions of small-subunit ribosomal RNA genes. PLoS ONE 4: e6372.

Bent SJ, Forney LJ. (2008). The tradegy of the uncommon: understanding limitations in the analysis of microbial diversity. ISME J 2: 689-695.

Chau KW. (2007). Integrated water quality management in Tolo Harbor, Hong Kong: a case study. J Cleaner Prod 15: 1568-1572.

Cheung MK, Chu KH, Li CP, Kwan HS, Wong CK. (2008). Genetic diversity of picoeukaryotes in a semi-enclosed harbor in the subtropical western Pacific Ocean. Aquat Microb Ecol 53: 295-305.

Countway PD, Gast RJ, Dennett MR, Savai P, Rose JM, Caron DA. (2007). Distinct protistan assemblages characterize the euphotic zone and deep sea $(2500 \mathrm{~m})$ of the western North Atlantic (Sargasso Sea and Gulf Stream). Environ Microbiol 9: 1219-1232.

Cuvelier ML, Ortiz A, Kim E, Moehlig H, Richardson DE, Heidelberg JF et al. (2008). Widespread distribution of a unique marine protistan lineage. Environ Microbiol 10: 1621-1634.

Díez B, Pedrós-Alió C, Massana R. (2001). Study of genetic diversity of eukaryotic picoplankton in different oceanic regions by small-subunit rRNA gene cloning and sequencing. Appl Environ Micobiol 67: 2932-2941.

Doyle JJ, Doyle JL. (1990). Isolation of plant DNA from fresh tissue. Focus 12: 13-15.

Elwood HJ, Olsen GJ, Sogin ML. (1985). The small-subunit ribosomal RNA gene sequences from the hypotrichous ciliates Oxytricha nova and Stylonychia pustulata. Mol Biol Evol 2: 399-410.

Forns X, Bukh J, Purcell RH, Emerson SU. (1997). How Escherichia coli can bias the results of molecular cloning: preferential selection of defective genomes of hepatitis $\mathrm{C}$ virus during the cloning procedure. Proc Natl Acad Sci USA 94: 13909-13914.

Galand PE, Casamayor EO, Kirchman DL, Potvin M, Lovejoy C. (2009). Unique archaeal assemblages in the Arctic Ocean unveiled by massively parallel tag sequencing. ISME J 3: 860-869.

Grime JP. (1973). Competitive exclusion in herbaceous vegetation. Nature 242: 344-347. 
Guillou L, Viprey M, Chambouvet A, Welsh RM, Kirkham AR, Massana R et al. (2008). Widespread occurrence and genetic diversity of marine parasitoids belonging to Syndiniales (Alveolata). Environ Microbiol 10: 3349-3365.

Hong Kong Environmental Protection Department (2003). Marine Water Quality in Hong Kong for 2002. Government Printer, Hong Kong.

Huse SM, Huber JA, Morrison HG, Sogin ML, Welch DM. (2007). Accuracy and quality of massively parallel DNA pyrosequencing. Genome Biol 8: R143.

Irigoien X, Huisman J, Harris RP. (2004). Global biodiversity patterns of marine phytoplankton and zooplankton. Nature 429: 863-867.

Kunin V, Engelbrekston A, Ochman H, Hugenholtz P. (2009). Wrinkles in the rare biosphere: pyrosequencing errors can lead to artificial inflation of diversity estimates. Environ Microbiol 12: 118-123.

Lefranc M, Thnot A, Lepre C, Debroas D. (2005). Genetic diversity of small eukaryotes in lakes differing by their trophic status. Appl Environ Microbiol 71: 5935-5942.

Li W, Godzik A. (2006). Cd-hit: a fast program for clustering and comparing large sets of protein or nucleotide sequences. Bioinformatics 22: 1658-1659.

Li WKW. (1994). Primary production of prochlorophytes, cyanobacteria, and eucaryotic ultraphytoplankton: measurements from flow cytometric sorting. Limnol Oceanogr 39: 169-175.

López-García P, Rodriguez-Valera F, Pedrós-Alió C, Moreira D. (2001). Unexpected diversity of small eukaryotes in deep-sea Antarctic plankton. Nature 409: 603-606.

Lovejoy C, Vincent WF, Bonilla S, Roy S, Martineau MJ, Terrado $\mathrm{R}$ et al. (2007). Distribution, phylogeny, and growth of cold-adapted picoprasinophytes in Arctic seas. J Phycol 43: 78-89.

Luo Q, Krumholz LR, Najar FZ, Peacock AD, Roe BA, White DC et al. (2005). Diversity of the microeukaryotic community in sulfide-rich Zodletone Spring (Oklahoma). Appl Environ Microbiol 71: 6175-6184.

Mackey D, Blanchot J, Higgins H, Neveux J. (2002). Phytoplankton abundances and community structure in the equatorial Pacific. Deep-Sea Res II 49: 2561-2582.

Margulies M, Egholm M, Altman WE, Attiya S, Bader JS, Bemben LA et al. (2005). Genome sequencing in microfabricated high-density picolitre reactors. Nature 437: $376-380$.

Massana R, Balague V, Guillou L, Pedrós-Alió C. (2004). Picoeukaryotic diversity in an oligotrophic coastal site studied by molecular and culturing approaches. FEMS Microbiol Ecol 50: 231-243.

Molvaer J, Knutzen J, Magnusson J, Rygg B, Skei J, Sorensen J. (1997). Environmental Quality Classification in Fjords and Coastal Areas. Statens Forurensningstilsyn TA-1467, Norway, p 36.

Moon-van der Staay SY, De Wachter R, Vaulot D. (2001). Oceanic $18 \mathrm{~S}$ rDNA sequences from picoplankton reveal unsuspected eukaryotic diversity. Nature 409: 607-610.

Not F, Massana F, Latasa M, Marie D, Colson C, Eikrem W et al. (2005). Late summer community composition and abundance of photosynthetic picoeukaryotes in Norwegian and Barents Seas. Limnol Oceanogr 50: 1677-1686.

Not F, Valentin K, Romari K, Lovejoy C, Massana R, Töbe K et al. (2007). Picobiliphytes: a marine picoplanktonic algal group with unknown affinities to other eukaryotes. Science 315: 253-254.

Park S-J, Park B-J, Pham VH, Yoon D-N, Kim S-K, Phee S-K. (2008). Microeukaryotic diversity in marine environments, an analysis of surface layer sediments from the East Sea. J Microbiol 46: 244-249.

Roman M, Gauzens AL, Rhinehart WK, White J. (1993). Effects of low oxygen water on Chesapeake Bay zooplankton. Limnol Oceanogr 38: 1603-1614.

Romari K, Vaulot D. (2004). Composition and temporal variability of picoeukaryote communities at a coastal site of the English Channel from 18S rDNA sequences. Limnol Oceanogr 49: 784-798.

Sherr EB, Sherr BF. (2000). Marine microbes. An overview. In: Kirchman, DL (ed). Microbial Ecology of the Oceans. Wiley-Liss: New York, pp 13-46.

Sogin ML, Morrison HG, Huber JA, Welch DM, Huse SM, Neal PR et al. (2006). Microbial diversity in the deep sea and the underexplored 'rare biosphere'. Proc Natl Acad Sci USA 103: 12115-12120.

Stoeck T, Epstein S. (2003). Novel eukaryotic lineages inferred from small-subunit rRNA analyses of oxygendepleted marine environments. Appl Environ Microbiol 69: 2657-2663.

Vaulot D, Eikrem W, Viprey M, Moreau H. (2008). The diversity of small eukaryotic phytoplankton $(\leqslant 3 \mu \mathrm{m})$ in marine ecosystems. FEMS Microbiol Rev 32: 795-820.

Viprey M, Guillou L, Ferréol M, Vaulot D. (2008). Wide genetic diversity of picoplanktonic green algae (Chloroplastida) in the Mediterranean Sea uncovered by a phylum-biased PCR approach. Environ Microbiol 10: 1804-1822.

Wear RG, Thompson GB, Stirling HP. (1984). Hydrography, nutrients and plankton in Tolo Harbor, Hong Kong. Asian Mar Biol 1: 59-75.

Wong CK, Wong CK. (2003). HPLC pigment analysis of marine phytoplankton during a red tide occurrence in Tolo Harbor, Hong Kong. Chemosphere 52: 1633-1640.

Worden AZ. (2006). Picoeukaryote diversity in coastal waters of the Pacific Ocean. Aquat Microb Ecol 43: $165-175$.

Worden AZ, Not F. (2008). Ecology and diversity of picoeukaryotes. In: Kirchman, DL (ed). Microbial Ecology of the Oceans 2nd edn. Wiley-Liss: New York, pp 159-205.

Zhu F, Massana R, Not F, Marie D, Vaulot D. (2005). Mapping of picoeukaryotes in marine ecosystems with quantitative PCR of the 18S rRNA gene. FEMS Micorbiol Ecol 52: 79-92.

Zuendorf A, Bunge J, Behnke A, Barger KJ-A, Stoeck T. (2006). Diversity estimates of microeukaryotes below the chemocline of the anoxic Mariager Fjord, Denmark. FEMS Microbiol Ecol 58: 476-491.

Supplementary Information accompanies the paper on The ISME Journal website (http://www.nature.com/ismej) 